(2) Open Access Full Text Article

\title{
Interdisciplinary three-step strategy to treat aortic stenosis and coronary artery disease in a patient with end-stage chronic obstructive pulmonary disease
}

\author{
This article was published in the following Dove Press journal: \\ Therapeutics and Clinical Risk Management \\ 5 April 2012 \\ Number of times this article has been viewed
}

\author{
Sebastian Michel' \\ Amir K Bigdeli' \\ Andres Beiras-Fernandez ${ }^{2}$ \\ Christoph Schmitz' \\ Manuel Wolf' \\ Ralf Sodian' \\ Ingo Kaczmarek' \\ 'Department of Cardiac Surgery, \\ Ludwig Maximilians University \\ of Munich, Munich, Germany; \\ ${ }^{2}$ Department of Thoracic and \\ Cardiovascular Surgery, Goethe \\ University Frankfurt, Frankfurt am \\ Main, Germany
}

Background: Valvular aortic stenosis is a common disease in the elderly, often in multimorbid patients. It is often associated with coronary artery disease and peripheral artery disease. In this situation, the risk of conventional open-heart surgery is too high, and other treatment strategies have to be evaluated.

Case report: A 79-year-old female patient with severe aortic stenosis, coronary artery disease and end-stage chronic obstructive pulmonary disease suffering from dyspnea at rest and permanently dependent on oxygen was treated in three steps. Firstly, her pulmonary infection was treated with antibiotics for 7 days. Then, the left anterior descending artery was stented (bare-metal stent). In the same session, valvuloplasty of the aortic valve was performed. She was sent to rehabilitation to improve her pulmonary condition and took clopidogrel for 4 weeks. Finally, she underwent transapical aortic valve replacement. She was released to rehabilitation on postoperative day 12.

Conclusion: A combination of modern interventional and minimally invasive surgical techniques to treat aortic stenosis and coronary heart disease can be a viable option for multimorbid patients with extremely high risk in conventional open-heart surgery.

Keywords: aortic stenosis, transapical aortic valve replacement, minimally invasive cardiac surgery

\section{Introduction}

Severe aortic stenosis can only be treated adequately with some form of aortic valve replacement, either conventionally with a median (or partial) sternotomy and open-heart surgery, with a minimally invasive left thoracotomy on the beating heart (transapical), or via access over the peripheral vessels (transfemoral/transaxillary) without opening the chest at all. ${ }^{1-3}$ Sometimes, patients with aortic stenosis also have severe concomitant diseases which dramatically increase the risk of the standard surgical procedures. Treating these patients requires a multidisciplinary approach with a combination of procedures that are performed one after another.

Correspondence: Sebastian Miche Department of Cardiac Surgery, University Hospital Großhadern, Ludwig Maximilians University of Munich, Marchioninistraße 15, 81377 Munich, Germany Tel +498970950

Email sebastian.michel@med.unimuenchen.de

\section{Case report}

We report on a 79-year-old female patient who presented with dyspnea at rest (New York Heart Association IV) and chest pain. She had a history of smoking (63 pack years) and end-stage chronic obstructive pulmonary disease with a forced expiratory 
volume in 1 second $\left(\mathrm{FEV}_{1}\right)$ at admittance of $0.64 \mathrm{~L}$ and saturation at rest of $72 \%$. She took steroids orally, inhaled tiotropium bromide, steroids, and $\beta_{2}$-mimetics and had an indication for long-term oxygen therapy.

Echocardiography revealed severe aortic stenosis with an effective orifice area of $0.3 \mathrm{~cm}^{2}$, a mean gradient of $50 \mathrm{mmHg}$, and mitral regurgitation of $\mathrm{II}^{\circ}$. Ejection fraction was not impaired. Heart catheterization was performed because of a positive troponin test and showed coronary heart disease with stenoses in all three main vessels. The left anterior descending artery (LAD) was the biggest coronary artery, filling the chronically occluded right coronary artery retrograde. The circumflex artery was small. Computed tomography angiography revealed severe calcifications around the aortic arch and along the whole thoracic and abdominal aorta down to the femoral arteries which were only $6.5 \mathrm{~mm}$ in diameter (Figure 1). The patient had had thromboendarterectomy of the left internal carotid artery in 2003 and had a moderate stenosis of the right $(<70 \%)$. At admission, she was also suffering from pneumonia. Under these conditions, our anesthesiologists decided to postpone the aortic valve replacement surgery as she would not have been able to tolerate general anesthesia. A multidisciplinary approach was scheduled. Firstly, her infection was treated with antibiotics (tazobactam + piperacillin) for 7 days until leukocytes and C-reactive protein (CRP) normalized. Then we performed the first interventional step: the patient underwent cardiac catheterization and the LAD, which was the patient's largest and most important coronary artery, was dilated and a bare-metal stent was placed. The circumflex artery was small, and the right coronary artery was chronically occluded after myocardial infarction. In the same session, valvuloplasty of the aortic valve was performed successfully without neurological complications and a resulting effective orifice area of $0.9 \mathrm{~cm}^{2}$. After that, the patient was almost symptom-free but had aortic insufficiency of $\mathrm{II}^{\circ}$. She was sent to rehabilitation to improve her pulmonary condition and took clopidogrel for 4 weeks because of the new bare-metal stent (600 mg loading dose, followed by $75 \mathrm{mg}$ daily). At re-admission, lung function tests were repeated and showed an improved $\mathrm{FEV}_{1}$ with $1.33 \mathrm{~L}$. She was now in a better condition to tolerate general anesthesia, so we performed a transapical aortic valve replacement (Edwards SAPIEN Ø 26 mm; Edwards Lifesciences, Irvine, CA) using a left mini-thoracotomy ${ }^{2}$ in our hybrid-operating room with a heart-lung machine on standby.

The patient was weaned from the ventilator on the same day. She was in sinus rhythm, had no neurological symptoms, no dyspnea, and could be released to rehabilitation

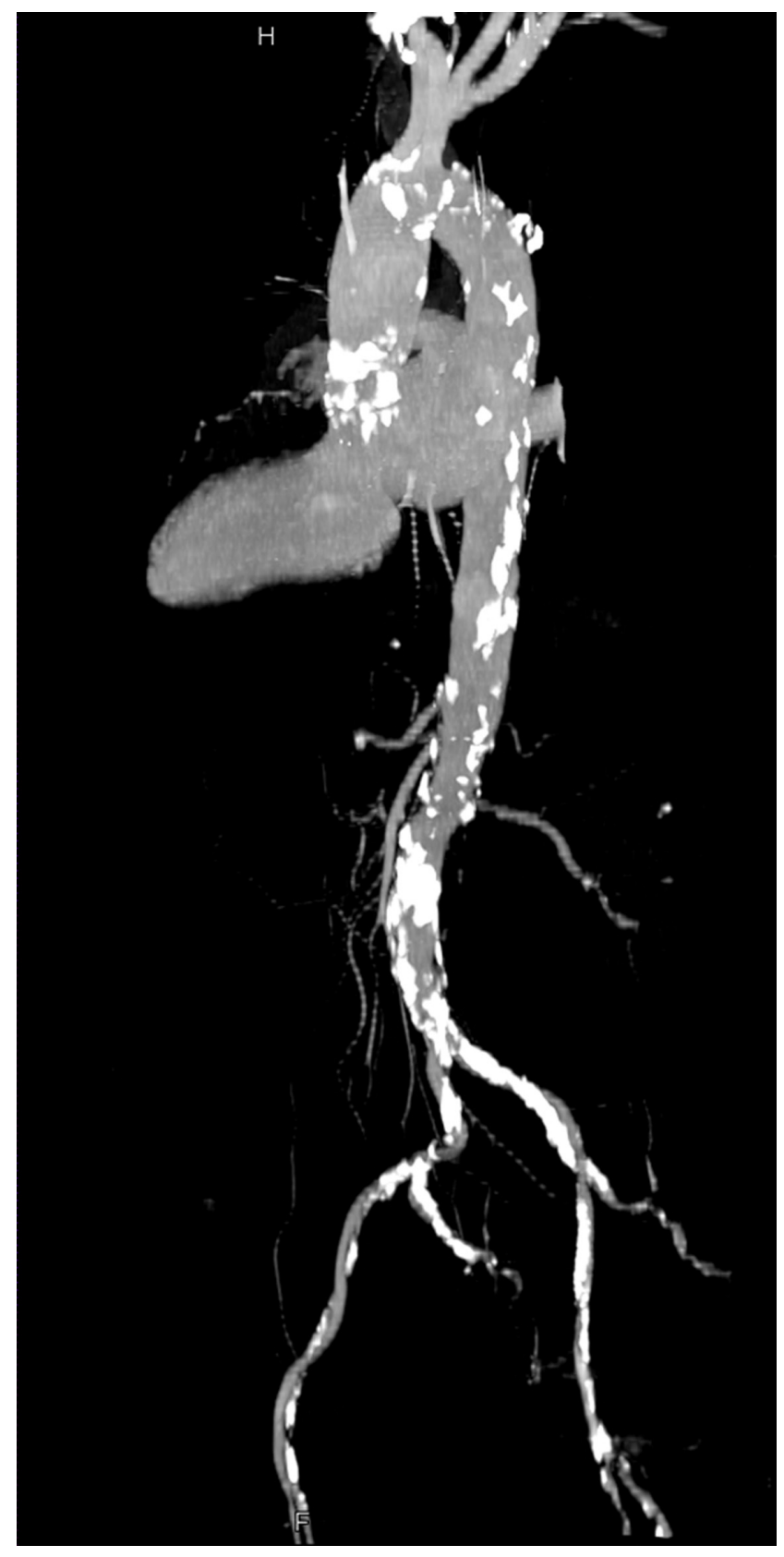

Figure I Computed tomography of the severely calcified aorta.

on postoperative day 12 . The patient was fine at 6-month follow-up.

\section{Discussion}

Regarding the coronary disease of our patient, we limited revascularization to the $\mathrm{LAD}$, as the circumflex artery was small and the right coronary artery chronically occluded after myocardial infarction. A bare-metal stent was chosen over a drug-eluting stent because double anti-platelet therapy is only required for a period of 4 weeks, just enough time to improve the pulmonary function and make general anesthesia 
with mechanical ventilation possible. Together with the stent implantation, aortic valvuloplasty was performed. This procedure helped reduce pulmonary congestion, which improved pulmonary functions.

Conventional aortic valve replacement with cardiopulmonary bypass under cardioplegic arrest is still the gold standard in the treatment of severe aortic valve stenosis and improves long-term survival compared to medical therapy. ${ }^{4}$

Without her comorbidities, our patient would have been a candidate for conventional open-heart surgery with aortic valve replacement (bioprosthesis) and coronary artery bypass grafting $(\mathrm{CABG})$, as the literature shows that even in older patients this procedure can be performed with low morbidity and mortality. ${ }^{5,6}$ In our patient's case, however, the logistic European System for Cardiac Operative Risk Evaluation predicted a mortality of $40 \%$ for the conventional surgical procedure. Furthermore, clamping of the extremely calcified aorta (Figure 1) would have posed a high risk for embolic stroke. Wound healing had to be considered in our patient because of her long-term steroid medication and osteoporosis. Regarding these last factors, the transapical approach with a lateral mini-thoracotomy was, in our opinion, much safer than a median sternotomy.

As the long-term results of valvuloplasty are poor ${ }^{7}$ and also inferior to transcatheter aortic valve implantation, ${ }^{8}$ some sort of aortic valve replacement had to be performed thereafter, to resolve the symptoms of the patient and thus improve her quality of life. If the femoral vessels had been large enough $(>6.5 \mathrm{~mm}$ in diameter for the Medtronic CoreValve delivery sheath which is 18 French) and free of calcifications, the transfemoral access would have been the method of choice because it can be performed without general anesthesia. If there are a lot of calcifications and the vessel is relatively small, as in our case, the risk for peripheral emboli could be reduced using the antegrade (transapical) access. ${ }^{9}$ For all these reasons, we decided to perform a transapical aortic valve replacement.

\section{Conclusion}

A combination of modern interventional and minimally invasive surgical techniques to treat aortic valve stenosis and

Therapeutics and Clinical Risk Management

\section{Publish your work in this journal}

Therapeutics and Clinical Risk Management is an international, peerreviewed journal of clinical therapeutics and risk management, focusing on concise rapid reporting of clinical studies in all therapeutic areas, outcomes, safety, and programs for the effective, safe, and sustained use of medicines. This journal is indexed on PubMed Central, CAS, coronary heart disease can be a viable option for multimorbid patients with an extremely high risk for conventional openheart surgery. These procedures should then be carried out only in experienced centers with a hybrid-operating room and in a multidisciplinary approach where all kinds of complications, eg, dissection of the femoral vessels, stroke, rhythm disorders, etc, can be handled sufficiently. A cardiac surgeon and a heart-lung machine should always be on standby.

For most patients however, treatment of aortic valve stenosis with valve replacement under cardioplegic arrest remains the gold standard until the long-term durability of interventional valve prostheses is fully evaluated in prospective randomized trials.

\section{Disclosure}

The authors report no conflicts of interest in this work.

\section{References}

1. ElBardissi AW, Shekar P, Couper GS, Cohn LH. Minimally invasive aortic valve replacement in octogenarian, high-risk, transcatheter aortic valve implantation candidates. $J$ Thorac Cardiovasc Surg. 2011;141(2):328-335.

2. Ye J, Cheung A, Lichtenstein SV, et al. Six-month outcome of transapical transcatheter aortic valve implantation in the initial seven patients. Eur J Cardiothorac Surg. 2007;31(1):16-21.

3. Cribier A, Eltchaninoff $\mathrm{H}$, Bash A, et al. Percutaneous transcatheter implantation of an aortic valve prosthesis for calcific aortic stenosis: first human case description. Circulation. 2002;106(24):3006-3008.

4. Schwarz F, Baumann P, Manthey J, et al. The effect of aortic valve replacement on survival. Circulation. 1982;66(5):1105-1110.

5. Likosky DS, Sorensen MJ, Dacey LJ, et al. Long-term survival of the very elderly undergoing aortic valve surgery. Circulation. 2009; 120 Suppl 11:S127-S133.

6. Alexander KP, Anstrom KJ, Muhlbaier LH, et al. Outcomes of cardiac surgery in patients $>$ or $=80$ years: results from the National Cardiovascular Network. J Am Coll Cardiol. 2000;35(3):731-738.

7. Otto CM, Mickel MC, Kennedy JW, et al. Three-year outcome after balloon aortic valvuloplasty. Insights into prognosis of valvular aortic stenosis. Circulation. 1994;89(2):642-650.

8. Leon MB, Smith CR, Mack M, et al. Transcatheter aortic-valve implantation for aortic stenosis in patients who cannot undergo surgery. $N$ Engl J Med. 2010;363(17):1597-1607.

9. Boone RH, Altwegg LA, Masson J-B, et al. Transcatheter aortic valve implantation in 168 high-risk patients with symptomatic severe aortic stenosis - single centre experience [abstract 3044]. Circulation. 2008; 118 Suppl:S807.

EMBase, Scopus and the Elsevier Bibliographic databases. The manuscript management system is completely online and includes a very quick and fair peer-review system, which is all easy to use. Visit http://www.dovepress.com/testimonials.php to read real quotes from published authors. 